\title{
Optimalisasi Koordinasi Relay Arus Lebih Kapal Bulk Carrier 50.000 DWT(Dead Weight Ton) Menggunakan Metode Genetic Algorithm
}

\author{
Rahim Atmanegara ${ }^{1}$, Istiyo Winarno ${ }^{2}$, Iradiratu DPK ${ }^{3}$, Belly Yan Dewantara ${ }^{4}$, Daeng Rahmatullah ${ }^{5}$ \\ 1,2,3,4,5 Teknik Elektro Fakultas Teknik dan Ilmu Kelautan, Universitas Hang Tuah Surabaya \\ J1. Arief Rachman Hakim no 105, Sukolilo, Surabaya 60111, Jawa Timur \\ e-mail: rahim.atmanegara@gmail.com ${ }^{1}$
}

\begin{abstract}
Abstrak - Koordinasi sistem pengaman sangat diperlukan dalam mengatasi gangguan yang terjadi pada sistem tenaga listrik, sehingga gangguan-gangguan yang terjadi dapat diatasi dari sistem yang sedang berjalan. Begitu juga dengan keamanan pada sistem kelistrikan pada Kapal Bulk Carrier 50.000 DWT (Dead weight Ton) dibutuhkan koordinasi sistem pengamanan yang tepat. Dengan mengaplikasikan prinsip koordinasi relay, maka urutan kerja peralatan pengaman sepanjang saluran dari sumber sampai pada beban harus diperhatikan. Koordinasi relay ini mencakup dari main switch board power supply sampai distribusi panel (pembebanan) dan perhitungan yang di ambil mulai dari kabel, relay, kapasitas relay, dan pembebanan dimulai dari main switch board sampai ke beban. Setelah dilakukan perhitungan yang tepat selanjutnya peneliti menggunakan metode Genetic Algorithm untuk mengoptimalkan koordinasi relay arus lebih tersebut. Dengan metode Genetic Algorithm didapatkan nilai setting TMS (Time Multiplier Setting) pada relay $1=0,9 \mathrm{~s}, \mathrm{~T}=1,76 \mathrm{~s}, \mathrm{Ip}=162,14 \mathrm{~A}$, I set Pickup $=$ $0,23 \mathrm{~A}$, I set Definite $=1,1 \mathrm{~A}$, pada relay $2 \mathrm{Tms}=1,1 \mathrm{~s}, \mathrm{~T}=1,69 \mathrm{~s}, \mathrm{Ip}=130,57 \mathrm{~A}$, I set Pickup = 2,9 A, I set Definite = 16,86 A, pada relay $3 \mathrm{Tms}=0,31 \mathrm{~s}, \mathrm{~T}=0,39 \mathrm{~s}$, Ip $=109,25 \mathrm{~A}$, I set Pickup $=2,42 \mathrm{~A}$, I set Definite $=16,61$ A. Adapun software yang digunakan adalah Matlab (R2009b) dan ETAP 12. Dengan menambahkan metode tersebut pada penelitian ini, diharapkan koordinasi relay arus lebih akan menjadi lebih optimal.
\end{abstract}

Kata kunci : relay arus lebih, Genetic Algorithm, koordinasi relay

\begin{abstract}
Security system coordination is very important to solve any trouble in electrical power system, That's trouble can be solved from the system have been working, So That's why to security electrical power system in Bulk Carrier ship with 50.000 Dead Weight Ton must be requiring a good coordination security system appropriate. By applying principle relay coordination, so the work step which of security equipment channels from the source until electrical load must be controlled. The relay Coordination is include from main switch board power supply until distribution panel and It's need calculation from wire, relay, relay capacity, and the loading have took from main switch board until load. Researcher will be using genetic algorithm method after all Calculation has been done which for optimization overcurrent relay coordination. By using Genetic Algorithm method be obtained value of TMS (Time multiplier Setting) in relay $1=0,9 \mathrm{~s}, \mathrm{~T}=1,76 \mathrm{~s}, \mathrm{Ip}=162,14 \mathrm{~A}, \mathrm{I}$ set Pickup =0,23 A, I set Definite $=1,1 \mathrm{~A}$, and in the Relay $2 \mathrm{Tms}=1,1 \mathrm{~s}, \mathrm{~T}=1,69 \mathrm{~s}, \mathrm{Ip}=130,57 \mathrm{~A}$, I set Pickup = 2,9 A, I set Definite = 16,86 A, in relay $3 \mathrm{Tms}=0,31 \mathrm{~s}, \mathrm{~T}$ $=0,39 \mathrm{~s}, \mathrm{Ip}=109,25 \mathrm{~A}$, I set Pickup = 2,42 A, I set Definite =16,61 A. The software will be used in this research is Mathlab R2009B software and Electrical Transient Analyzer Program. By using that's method it might the relay coordination will be optimal.
\end{abstract}

Keywords: Overcurrent Relay, Genetic Algorithm (GA), Relay Coordination

\section{PENDAHULUAN}

Semakin meningkatnya pertumbuhan industri disektor kemaritiman maka harus diimbangi pula dengan standar kelayakan pada kapal pelayaran. Sehubungan dengan standar kelayakan pada kapal, salah satu yang terpenting adalah pada sistem keamanan kelistrikan kapal tersebut. Keamanan pada sistem kelistrikan kapal melakukan pengamanan terhadap beban-beban yang ada di kapal untuk penggunaan setiap kebutuhan yang ada di kapal, dari sekedar pengamanan untuk beban yang berskala kecil maupun besar, keamanan untuk sebuah beban yang di proteksi oleh relay yang bekerja membuka atau penutup rangkaian listrik dalam kondisi tertentu. Relay pada dasarnya adalah saklar yang membuka dan menutupnya (open dan close) dengan tenaga listrik melalui coil relay yang terdapat di dalamnya. Pada awalnya sebuah relay di 
anggap memiliki coil/lilitan tembaga/cooper yang melilit pada sebatang logam, pada saat coil diberi masukan arus/tegangan listrik maka coil akan membuat medan elektromagnetik yang mempengaruhi batang logam di dalam lingkarannya tersebut untuk menjadikannya sebuah magnet. Kekuatan magnet yang terjadi pada batang logam tersebut menarik lempeng logam lain yang terhubung melalui armature/tuas ke sebuah saklar. Biasanya relay memicu saklar terbuka dan tertutup, dan hal ini tergantung tipe dan kebutuhan. Dengan kemajuan jaman relay tidak lagi identik dengan perangkat mekanis. Salah satu metode yang dilakukan untuk memperoleh keandalan sistem adalah koordinasi rele pengaman dengan memfungsikan rele sebagai pengaman utama dan pengaman cadangan. Proteksi cadangan ini umumnya mempunyai perlambatan waktu (time delay), hal ini untuk memberikan kesempatan kepada poteksi utama beroperasi terlebih dahulu, dan jika proteksi utama gagal baru proteksi cadangan yang akan beroperasi . Untuk memenuhi fungsi tersebut maka waktu rele pengaman utama disetel lebih cepat daripada rele pengaman cadangan. Rele pengaman dengan kemampuan selektif yang baik dibutuhkan untuk mencapai keandalan sistem yang tinggi karena tindakan pengaman yang cepat dan tepat akan dapat mengisolir gangguan dan seminimal mungkin. Relay yang digunakan untuk mengatasi gangguan hubung singkat dengan over current relay. Maka untuk mengoptimalkan kinerja koordinasi rele arus lebih yang dipasang pada sistem instalasi tersebut perlu adanya metode yang mampu mengoptimalkan koordinasi dari rele arus lebih tersebut. Pada skripsi ini menggunakan Genetic Algorithm (GA). Genetic Algorithm (GA) merupakan algoritma yang cukup baik untuk proses optimalisasi. Oleh karena itu, pada skripsi ini penulis akan menggunakan metode tersebut untuk algorithm merupakan algoritma komputasi yang diinspirasi teori evolusi yang kemudian diadopsi menjadi algoritma komputasi untuk mencari solusi suatu permasalahan dengan cara yang lebih "alamiah", algoritma genetik juga merupakan algoritma pencarian secara heuristik. Salah satu fungsinya ialah untuk mencari solusi atas permasalahan optimasi kombinasi, yaitu mendapatkan suatu nilai solusi optimal terhadap suatu permasalahan yang mempunyai banyak kemungkinan solusi.

\section{METODOLOGI}

\section{A. Diagram Alur}

Berdasarkan data yang di peroleh berikut adalah diagram alir atau flowchart dari percobaan ini yang ditunjukkan gambar 1 dibawah. Diagram alir ini dimulai dari masuknya data dari kurang atau lebihnya frekuensi, tegangan, fasa, over kapasitas. data pada kapal di input dengan mensimulasikan menggunakan etap 6.0.0 power plot kemudian dilakukan permodelan sistem kelistrikan kapal. Selanjutnya apakah terjadi error pada simulasi, jika tidak langkah selanjutnya melakukan perhitungan. Bila salah satu beban mengalami kelebihan atau kekurangan maka koordinasi relay akan bekerja lebih cepat mengamankan beban yang terkena gangguan tanpa harus mematikan seluruh proteksi yang ada didalam suatu sistem distribusi di kapal dengan menggunakan metode kombinasi antara arus dan waktu, akan dapat diperoleh perhitungan yang memenuhi kapasitas beban tersebut. Setelah terjadi perhitungan relay maka akan diperoleh data relay yang akan dimasukan dan diproses menggunakan algoritma genetika untuk mengoptimalisasi koordinasi relay tersebut. Proses ini dilakukan di software MATLAB dimana hasil yang diperoleh nantinya diharapkan akan mendapatkan koordinasi relay arus lebih yang lebih optimal untuk koordinasi relay utama dan backup.

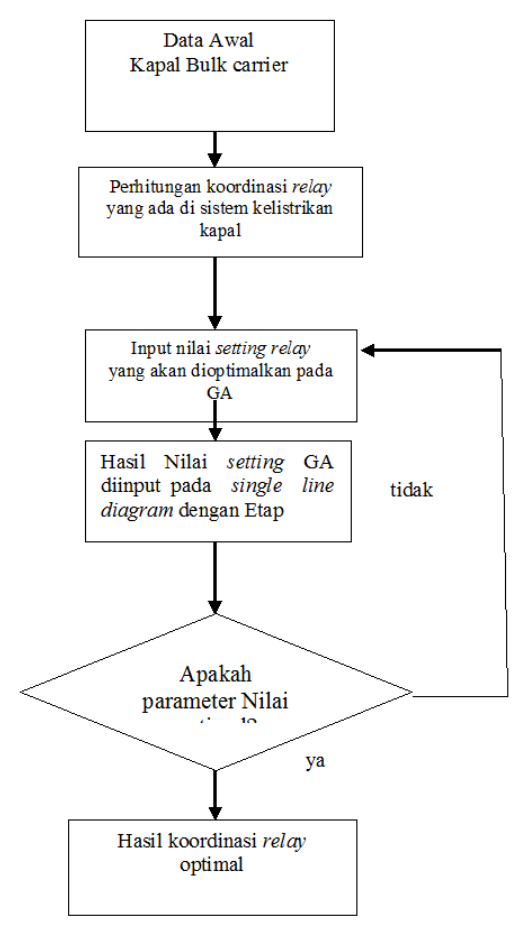

Gambar 1. Diagram Alir pelaksanaan penelitian

\section{B. Single Line Diagram Pada Bulk Carrier 50.000 DWT pad ETAP 12}

Gambar di bawah ini menunjukkan wiring diagram main switch board kapal Bulk Carrier 50.000 DWT pada software ETAP 12 secara umum, yaitu terdiri dari GSP1, GSP 2, FEED PANEL 1, FEED PANEL 2, FEED PANEL 3, dan FEED PANEL 4. Berikut ini adalah wiring diagram secara lengkap main switch board kapal bulk carrier 50.000 DWT yang telah penulis tambahkan komponen relay arus lebih untuk mengetahui koordinasi relay yang tepat..

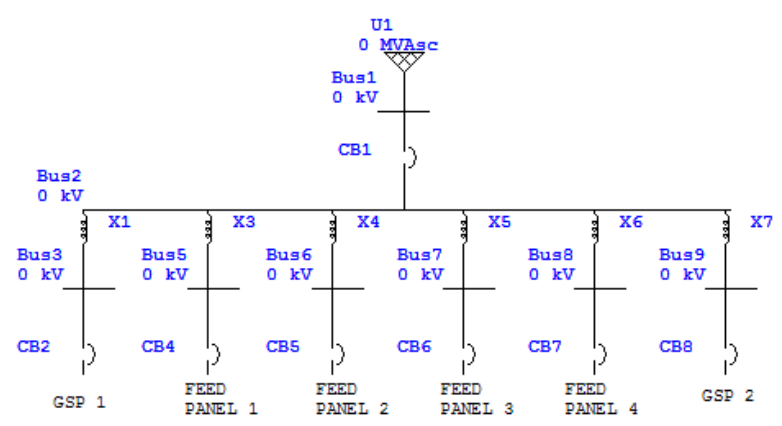

Gambar 2. Single Line Diagram Kapal Bulk Carrier 50.000 DWT 


\section{Simulasi Hubung Singkat Pada ETAP 12}

Setelah didapatkan single line diagram pada ETAP 12 langkah selanjutnya dilakukan simulasi hubung singkat Isc Min 30 cycle dan Isc Max $1 / 2$ cycle.

Tabel 1. Data Hubung singkat Isc min 30 cycle dan Isc max $1 / 2$ cycle

\begin{tabular}{ccccc}
\hline BUS & \multicolumn{2}{c}{ Isc $\max ^{1 / 2}$ cycle } & \multicolumn{2}{c}{ Isc min 30 cycle } \\
\hline ID & KV & KA & KV & KA \\
\hline Bus 106 & 0,39 & 3,57 & 0,26 & 1,28 \\
Gsp 1 Bus 1 & 0,39 & 3,56 & 0,26 & 1,28 \\
Gsp 1 Bus 2 & 0,39 & 3,56 & 0,26 & 1,28 \\
Gsp 2 Bus 98 & 0,39 & 3,57 & 0,26 & 1,28 \\
Gsp 2 Bus 103 & 0,39 & 3,57 & 0,26 & 1,28 \\
Gsp 1 Bus 7 & 0,39 & 3,56 & 0,26 & 1,28 \\
Feed 4 Bus 77 & 0,39 & 3,57 & 0,26 & 1,28 \\
Feed 4 Bus 81 & 0,39 & 3,57 & 0,26 & 1,28 \\
\hline
\end{tabular}

Dari data tersebut dapat Hubung singkat minimum adalah hubung singkat 2 fasa pada 30 cycle. Sedangkan hubung singkat maksimum adalah hubung singkat 3 fasa pada $1 / 2$ cycle. Hubung singkat maksimum $1 / 2$ cycle digunakan untuk setting relay dengan setting kelambatan waktu $0,1 \mathrm{~s}$, karena jika dikonversi ke besaran waktu maka $1 / 2$ cycle sama dengan $0,08 \mathrm{~s}$. Sedangkan 30 cycle digunakan untuk setting relay dengan setting kelambatan waktu $0,4 \mathrm{~s}$, jika dikonversi ke besaran waktu maka 30 cycle sama dengan $0,6 \mathrm{~s}$.

Sebelum melakukan simulasi optimasi, terlebih dahulu ditentukan karakteristik relay yang digunakan, pada penelitian ini digunakan karakteristik relay very invers time dengan rumus setting relay.

$$
\mathrm{t}=\frac{13_{x} 5}{\left(\frac{\mathrm{I}}{\mathrm{Ip}}\right)^{1-1}} . \operatorname{TDS}(\mathrm{TMS})
$$

Parameter utama yang ditentukan apakah perencanaan koordinasi waktu relay dan selisih (margin) antara waktu operasi relay - relay yang letaknya berdekatan dalam single line diagram sistem tersebut.

\section{Pemrogaman menggunakan Mathlab R2009b}

Perancangan program simulasi optimasi ini mnggunakan Software Mathlab R2009b dengan metode optimasi genetic algorithm dalam 7 tahap yaitu menentukan parameter optimasi, membangun fungsi obyektif, Evaluasi nilai fitness, seleksi, , crossover, mutasi, dan terminasi. Fungsi obyektif dapat dirumuskan dalam bentuk matematis sebagai berikut.

\section{Obyektif Function $=$}

$\alpha \mathrm{x} \sum(\mathrm{T} \text { relay }-\mathrm{T} \text { perhitungan })^{2}+\beta \times \sum(\mathrm{TMS}-(\mathrm{TMS}$ perhitungan $))^{2}+\mu \times \sum(\mathrm{IP}-(\text { IP perhitungan }))^{2}$

\section{HASIL DAN PEMBAHASAN}

\section{A. Proses Optimasi Genetika menggunakan Software Mathlab R2009b}

Proses pembangkitan kromosom yaitu dialkukan otomatis dimana Didalam kromosom yang dibangkitkan terdapat yaitu suatu gen dimana gen tersebut adalah parameter yang dicari dan dibangkitkan. Berikut adalah gambar plot dari pembangkitan beberapa kromosom atau populasi

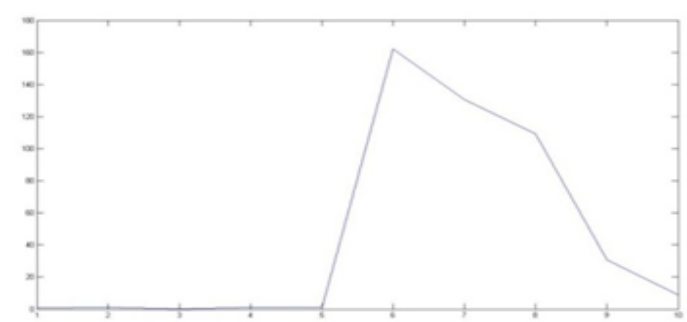

Gambar 3. Plot pembangkitan kromosom oleh genetic algorithm

Pada gambar plot diatas menunjukkan bahwa parameter 1 - 5 nlai yang didapat tdak lebih dari 2 karena parameter yang dibangkitkan adalah nilai dari TMS sedangkan pada parameter $6-10$ yang dibangkitkan adalah arus pick up untuk menentukan arus gangguan yang mengalir apakah relay menetukan suatu trip dari circuit breaker. Beberapa kromosom ini dibangkitkan secara acak selanjutnya dilakukan proses inisialisasi kromosom dimana memberikan nilai awal dengan memnetukan suatu batasan batasan yang telah ditentukan. Selanjutnya proses berupa perhitungan nilai fitnes, seleksi kromosom berupa roullete wheel, mutasi genetika dilakukan secara otomatis oleh toolbox dilakukan proses perhitungan yang sama sampai generasi selanjutmya menemukan solusi yang tepat. Pada proses optimasi ini digunakan suatu koefisien kontrol efektivitas dimana koefisen kontrol ini agar nilai fitness dari tiap parameter memenuhi suatu solusi yang tepat.

Gambar 4 menunjukkan operasi genetika mencari nilai fitness yang terbaik dari parameter Ip dan TMS relay 18, 19, 221, 222, dan 223.

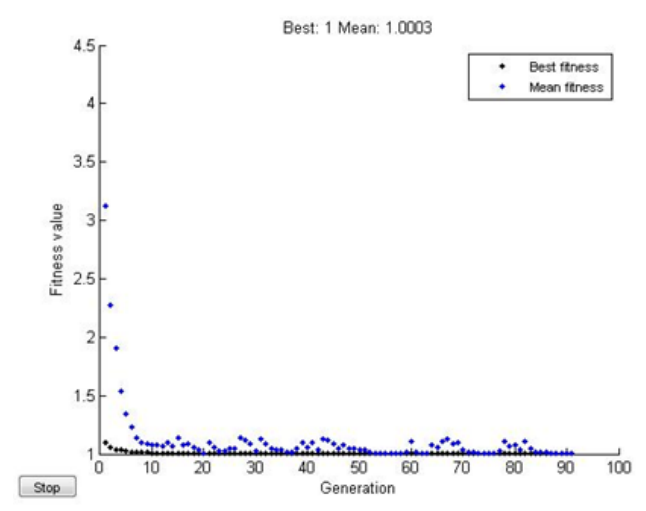

Gambar 4. Grafik pencarian nilai fitness terbaik 
Tabel 2. Data setting relay arus lebih menggunaka metode genetic algorithm

\begin{tabular}{|c|c|c|c|c|c|}
\hline NO & Relay & TMS & Ip & t operasi (s) & $\begin{array}{c}\text { I set } \\
\text { Pickup }\end{array}$ \\
\hline 1 & 18 Bus 1 & 0,99 & 102,01 & 1,16 & 2,26 \\
\hline 2 & 19 Bus 7 & 0,92 & 83,29 & 0,87 & 1,85 \\
\hline 3 & 221 Bus 77 & 0,71 & 32,30 & 0,25 & 1,615 \\
\hline 4 & 222 Bus 79 & 0,57 & 29,82 & 0,18 & 1,49 \\
\hline 5 & 223 Bus 79 & 0,50 & 7,55 & 0,04 & 0,37 \\
\hline
\end{tabular}

B. Simulasi koordinasi Relay 1,2 dan 3 dengan metode genetic algorithm pada ISC min 30 cycle

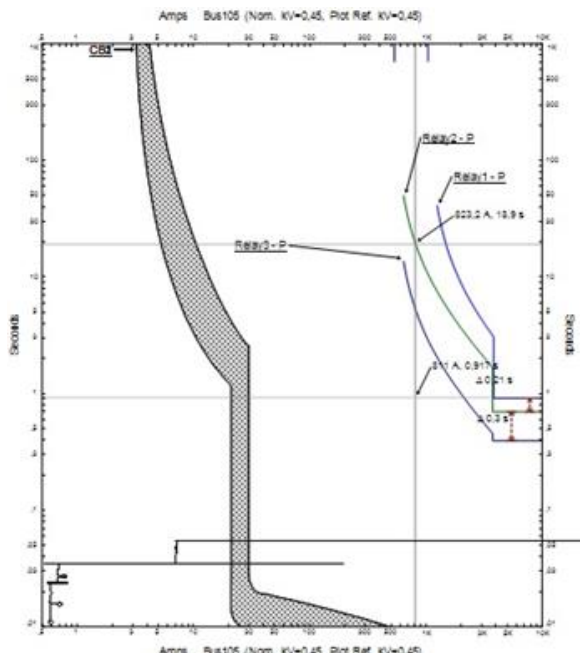

Gambar 5. Plot Kurva relay 1, 2, dan 3 dengan metode genetic algorithm

Terlihat bahwa hasil Plot relay 1, 2, dan 3 tidak terjadi kurva yang bersinggungan antar relay juga pada grading time antar relay masih memenuhi dari standar BS-42 yaitu $0,2-0,4 \mathrm{~s}$, begitu juga antara kurva relay 285,286 , dan 1 tidak bersinggungan dan grading time antar relay juga masih memenuhi standar akan tetapi telah terjadi pertukaran kurva yaitu yang seharusnya posisi plot kurva relay 285 menempati 286 begitu juga sebaliknya karena arus pickup relay 285 lebih besar dari relay 286.

C. Simulasi koordinasi Relay 18, 19 dan 3 dengan metode genetic algorithm pada ISC min 30 cycle

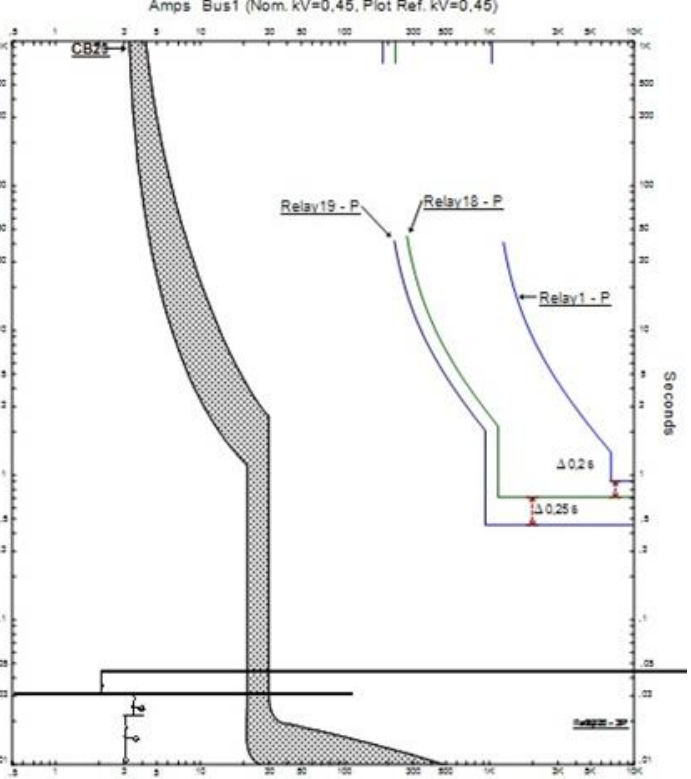

Gambar 6. Respon Arus/Tegangan Konverter Buck-Boost

Terlihat pada GSP 1 Bus 7 pada relay 19 saat arus gangguan yang mengalir sebesar $6,4 \mathrm{kA}$ maka relay 19 bekerja pada $0,8 \mathrm{~s}$ juga pada relay 18 saat arus gangguan yang mengalir sebesar $8,3 \mathrm{kA}$ maka waktu kerja relay 18 pada $1,23 \mathrm{~s}$ grading time antar relay 19 dengan relay 18 sebesar $0,3 \mathrm{~s}$ begitu juga pada relay 1 menunjukkan arus sebesar 3,52 $\mathrm{kA}$ dan waktu kerja $4 \mathrm{~s}$ dan grading time antara Relay 18 dan 1 adalah $0,2 \mathrm{~s}$.

\section{KESIMPULAN}

Berdasarkan hasil yang didapatkan dari simulasi dan analisis pada penelitian ini, dapat diambil beberapa kesimpulan sebagai berikut:

1. Dengan melakukan pencarian menggunakan proses optimasi genetika atau metode genetic algorithm dengan pengujian tool star protection ETAP 12 pada relay kapal bulk carrier 50.000 DWT yang diujikan grading time antar relay berkisar antara $0,21-0,4 \mathrm{~s}$, sudah memenuhi dari standard yang ditentukan oleh BKI (Badan Klasifikasi Indonesia) pada bagian Listrik kapal bab 4 Proteksi Instalasi dan distribusi point 2.2.1 yaitu grading time kordinasi kerjadari relay pengaman pada proteksi arus hubung singkat berkisar antara $0,2-0,5 \mathrm{~s}$.

2. Pencarian menggunakan metode genetic algorithm dapat menoptimalkan yaitu dengan kurva antar relay sudah tidak bersinggungan.

\section{REFERENSI}

[1] K. P. Manjhusa 2013 Comparison Of Over Current Relay Coordination By Using Fuzzy And Genetic Algorithm Methods [Jurnal]. Nagpur. Priyadarshini Institute of Engineering and Technology.

[2] Bonar P. 2012. Praktik-Praktik Proteksi Sistem Tenaga Listrik. Yogyakarta: Penerbit Andi.

[3] Imam R. 2009. Desain Sistem Tenaga Modern, Yogyakarta: Andi Offset

[4] Triadi N. 2005. Optimalisasi Sistem Distribusi Tenaga Listrik pada Kapal Cargo Bulk Carrier 15.000/18.500 dwt [Skripsi]. Surabaya. Universitas Hang Tuah. 
[5] Agiel T, Karnoto, Susatyo H. 2010. Optimasi Kinerja Rele Arus Lebih Berarah Pada Sistem Pembangkitan Terdistribusi Menggunakan Algoritma Genetika. Semarang: Universitas Diponegoro Semarang

[6] Wisnu D. 2016. Koordinasi Relay Pada Sistem Kelistrikan Kapal Bulk Carrier 50.000 DWT(Dead Weight Ton) Dengan Metode Fuzzy Logic. Surabaya. Universitas Hang Tuah.

[7] Robert H. 2009. Koordinasi Relay Arus Lebih Dengan Menggunakan Metode Algoritma Genetika. Teknik Elektro. Surabaya : Institut Teknologi Sepuluh Nopember.

[8] Zeineldin, Hatem H. Dkk. 2009. "Coordination of Directional Overcurrent Relay to Prevent Islanding of Distributed Generatiors". International Conference and Exhibition on Green Energy \& Sustainability for Arid Regions \& Mediterranean Countries, june 15172009.

[9] BS 142 Requirements for single input energizing quantity relays. 1990. Specification for single input energizing quantity measuring relays with dependent specified time. BS 142 Electrical protection relays Vol. 3, no 3.2, Desember

[10]BKI Rules For The Clasification And Construction Part 1 Seagoing Ships. 2016 . Rules For Electrical Instalation. BKI Instalation Protection and Power Distribution vol. 4, section 4 no. 2.2.1, Februari.

[11] Goldberg D. 1989. Genetic Algorithms in search, optimization, and Machine Learning ,Addison Wesley Publishing Company, Incorporated, Reading, Massachusetts. 